This is a so-called personal version (author's manuscript as accepted for publishing after the review process but prior to final layout and copyediting) of the article:

Mantere, Saku and Ketokivi, Mikko. Reasoning in Organization Science. Academy of Management Review, 2013, 38: 70-89.

Researchers are kindly asked to use the official publication in references.

\title{
REASONING IN ORGANIZATION SCIENCE
}

\begin{abstract}
Prescriptions regarding organization-scientific methodology are typically founded on the researcher’s ability to approach perfect rationality. In a critical examination of the use of scientific reasoning (deduction, induction, abduction) in organizational research, we seek to replace this unrealistic premise with an alternative that incorporates a more realistic view of the cognitive capacity of the researcher. Towards this end, we construct a typology of descriptive, prescriptive, and normative criteria for the evaluation of organization-scientific reasoning practices. This typology addresses both cognitive limits as well as the diversity of research approaches and research designs in organizational research. We make the case for incorporating not only the computational but also the cognitive element into both the reporting and the evaluation of scientific reasoning.
\end{abstract}




\section{INTRODUCTION}

The objective of scholarly reasoning is to justify new knowledge in a scientific field. The fundamental questions on the nature of organization-scientific knowledge creation, more generally, have been approached from many angles, ranging from epistemological concerns (Moldoveanu \& Baum, 2002) and the role of theoretical paradigms (Pfeffer, 1993), to social construction (Astley, 1985) and scientific rhetoric (Ketokivi \& Mantere, 2010; McCloskey, 1998). Conspicuously missing from extant literature is a methodological—as opposed to rhetorical, psychological, or social—account of scientific reasoning. The missing piece is crucial, because the general understanding of how scientists reason and develop explanations is surprisingly limited (Lipton, 2004), and yet, prescriptive norms are essential in defining criteria for methodological rigor. The problem is further exacerbated by the fact that existing prescriptive accounts do not incorporate the cognitive limitations of the researcher, which renders the resultant prescription unavoidably non-operational (Stanovich, 1999).

The paucity of the methodological literature on organization-scientific reasoning in particular is striking, because questions regarding the nature of human reasoning have always been at the heart of organizational scholarship. The literature on how managers reason and make decisions is as diverse as it is massive. Volumes of research have been devoted to rationality and the implications of cognitive limits such as bounded rationality and behavioral biases (e.g., Bazerman, 2002; Bell, Raiffa, \& Tversky, 1989; Eisenhardt \& Zbaracki, 1992; Kahneman, Slovic, \& Tversky, 1982; March, 1994; Simon, 1997; Stanovich, 1999). We continually report on and are puzzled at the intricacies, idiosyncrasies, and downright irrationalities of managerial reasoning (e.g., Green, 2004; Green, Li, \& Nohria, 2009) and emphatically call for more research. 
In stark contrast, methodological texts are written as if the reader were a rational actor who is able to overcome cognitive limitations through rigorous application of scientific reasoning principles. Our methodological writings candidly acknowledge that scientific research is a complex endeavor beset with numerous challenges, but the ability reason rationally—from one's data to a theoretical conclusion, for instance-is not considered one of these challenges. At the same time, unless we have strong reasons to believe that researchers are fundamentally different from managers in how they cognitively function, we know that prescriptions to eliminate cognitive constraints and biases are generally unrealistic. We typically do not consider "becoming more rational" as the remedy to bounded rationality.

In this paper, we start at the premise that researchers are just as human as managers and that there is little evidence that researchers face different cognitive constraints. Much like in reasonable managerial prescription, cognitive constraints must be incorporated to arrive at operational and reasonable methodological prescriptions. Drawing jointly on the literature on cognition and the methodological authorities in our field, we formulate three criteria to scientific reasoning—descriptive, prescriptive and normative (cf. Stanovich, 1999)—and suggest appropriate roles for each. As a result, we believe that a distinction and an appreciation of the different criteria and their roles will aid organizational scholars in their efforts towards robust reasoning and more generally, moves our field toward more actionable prescription.

\section{WHAT IS SOUND REASONING?}

The essence of an argument is proceeding from grounds to claims, or from premises to conclusions, in a credible manner (Toulmin, 2003). One of the primary tasks of organizational scholars, as scientists, is to use various reasoning principles to bridge premises with conclusions and to defend the claims made in these conclusions. Conversely, one of the primary tasks of the 
audience members, as scientists, is to evaluate whether the reasoning principles have been used in a sound manner. We start by a brief examination of the elementary forms of scientific reasoning.

\section{Forms of Reasoning: Deduction, Induction, Abduction}

Both in everyday life and in scientific inquiry, we use various forms of reasoning by which we draw conclusions on matters of importance: we argue for a case, we make generalizations, and we construct explanations and interpretations. To introduce the elementary forms of scientific reasoning, consider the classic illustration (Peirce, 1878):

1. All the beans in this bag are white (we label this the "Rule").

2. These beans are from this bag (we label this the "Explanation").

3. These beans are white (we label this the "Observation”).

Peirce's example can be read as a metaphor for the practice of reasoning in organizational research. We can think of the beans as our data and the bags as our theories: we collect data (pick beans), make empirical generalizations (make inferences about beans not observed), and accept some theories while dismissing others (pick bags).

Deductive reasoning takes the rule (1) and the explanation (2) as premises and derives the observation (3). In deduction, one draws a conclusion about the particular based on the general. The observation necessarily follows as a logical consequence of the rule and the explanation, which makes deduction, in a sense, methodologically uncontestable: while one may question the credibility of the premises in a deductive argument—one might reject the general rule as empirically incorrect, for instance — the act of reasoning itself is logically sound.

Deduction allows us to predict the color of the next handful of beans drawn from the bag. But if our task were to make inferences about the entire bag of beans, we would engage in 
inductive reasoning based on observed samples. Inductive reasoning combines the observation (3) and the explanation (2) to infer the rule (1) and thus, moves from the particular to the general. But an observation about the particular establishes a general rule in an incomplete sense; the rule does not logically follow from repeated observations. This is the well-known problem of induction (see Ketokivi \& Mantere, 2010, for a discussion in the context of organizational research).

Conventionally, deduction and induction have been considered the two basic forms of scientific reasoning. There is, however, a third variant of reasoning that merits attention: abduction (e.g., Peirce, 1878). Understanding the role of abduction becomes apparent once we acknowledge the possibility of multiple bags and uncertainty about which bag is the source of the observed beans. In abduction, one begins with a number of alternative rules (1) and the observation (3); the explanation (2) is inferred by appraising the alternative rules in light of the observation. Given the observation of white beans and the general rule that all the beans in the bag are white as well, one may reasonably infer that the beans came from the specific bag. This inference can be understood as an hypothesis that would make the observation of white beans matter of course. Turning "surprising facts" into matters of course is the general logic of abductive reasoning (Hanson, 1958: 86). Just like in induction, we have no logical grounds for drawing the conclusion: abduction is not only presumptive and conjectural, it is, strictly interpreted, a special case of the fallacy of affirming the consequent (Niiniluoto, 1999: 442). But from the point of view of reasoning practice, abductive reasoning is one of the primary reasoning tools we use, both in mundane decisions and in scientific inquiry (Hanson, 1958; Harman, 1965; Josephson \& Josephson, 1996; Lipton, 2004). Indeed, abduction has been suggested as the logic 
by which new hypotheses are derived and ultimately, how scientific discoveries are made (Hanson, 1958; Niiniluoto, 1999).

The three forms of reasoning constitute our primary tools of inference. In the general sense, deduction is an inference to a particular observation (or case), induction an inference to a generalization, and abduction an inference to an explanation. In summary, we predict, confirm, and disconfirm through deduction, generalize through induction, and theorize through abduction.

\section{Reasoning-as-Computation and Reasoning-as-Cognition}

Induction may be used to denote all "ampliative” forms of reasoning, that is, reasoning where the conclusion is not logically entailed in the premises (e.g., Hájek \& Hall, 2002). If we accept this general definition, induction becomes an umbrella term for a variety of non-deductive forms of reasoning, including abduction (Lipton, 2004). There has been a tendency among organization scientists to define induction in a much narrower sense, however. In traditions such as inductive case research (Eisenhardt, 1989), induction is de facto equated with eliminative (“Baconian”) induction (Ketokivi \& Mantere, 2010). In eliminative induction, propositions of increasing generality are inferred through a process of observing similarities among and differences between observations (Barker, 1957). Through iteration, the generality of observed properties and relations in the data is tested against more evidence, eliminating propositions that do not receive support and retaining the ones that do. One of the essential qualities of eliminative induction is researcher invariance: because the common properties and their relations are assumed to be essentially embedded in the data, any researcher looking at the same data will, by assumption, reason similarly and discover the same generalization. Consequently, inductive generalizations can indeed be claimed "to emerge" from the data (Brown \& Eisenhardt, 1997: 5). 
The view of reasoning underlying eliminative induction is computation, a researcherinvariant activity that bridges the premises with the conclusions. Computation here is not limited to mathematical operations with quantitative data: computation, in a general sense, means following explicit, logically coherent rules. Cognition is irrelevant and consequently, reasoning can be “abstracted from the mind” and programmed into algorithms (e.g., Thagard, 1988), which have for decades constituted the foundation of computerized expert systems (Simon, 1987: 60).

The limits of the computational view become particularly evident as one examines theory development. Theories are in a peculiar way always partly about the people who create them. Mintzberg (2005: 357) crystallizes the sentiment: “we don’t discover theory; we create it.” Theory building cannot thus be limited to a particular tradition of research: it is an activity conducted by cognitively idiosyncratic scholars (Lipton, 2004; Stanovich, 1999). When scientists engage in reasoning, they do not just compute, they also cognize. In contrast with reasoning by computation, reasoning by cognition has a crucial holistic component which cannot be implemented in algorithms (cf. Fodor, 2001).

Idiosyncrasy and cognition in scientific reasoning are not simply hypotheses, they have been empirically demonstrated: reasoning is simply not a researcher-invariant activity (Faust, 1984; Lipton, 2004; Piaget, 1971; Weimer, 1979). The cognitive view also receives unambiguous support from recent research in affective neuroscience: “[h]uman decision-making is not a purely verbal/mathematical process, but requires integration of cognitive and emotional processing” (Thagard, 2007: 371). The computational view is based on the unrealistic assumption that "people can disconnect their reasoning apparatus from the emotional machinery" (Thagard, 2007: 377). Cognitive, even emotional idiosyncrasies pervade our reasoning practices. 
In light of all the empirical evidence on reasoning, it is hardly surprising that objections to the notion that inductive reasoning can adequately be described (or prescribed) as computational are abundant in organizational research (Alvesson \& Kärreman, 2007; Ketokivi \& Mantere, 2010; Locke, Golden-Biddle, \& Feldman, 2008; Mintzberg, 2005; Suddaby, 2006; Van de Ven \& Johnson, 2006; Wodak, 2004). Abduction provides a useful formulation for extending reasoning to incorporate the cognitive aspect. First described by Peirce (e.g., Hartshorne \& Weiss, 1934), abduction involves an active researcher formulating — through at least partly idiosyncratic cognition—various generic statements as explanations or interpretations of the data. Another researcher looking at the very same data might well formulate a different set of statements. After weighing the merits of each explanation, the researcher then selects the "best" one (Harman, 1965; Peirce, 1878). There is, however, no single set of criteria for what constitutes "best” (Lipton, 2004; Lycan, 1988). This is particularly relevant to organization science, where theories make extensive use of non-observational concepts (Bagozzi \& Phillips, 1982; Godfrey \& Hill, 1995): "when the process of inference to the best explanation is extended to postulate non-empirical entities, there is no best explanation” (Boylan \& O'Gorman, 1995: 213).

The implications of incorporating the cognitive view of reasoning cannot be overstated. The computational view is based on the idea of a singular scientific method, indeed the scientific method, which many notable philosophers of science have promoted as the bedrock of scientific inquiry (e.g., Lakatos, 1970). The scientific method is based on the use of deduction and induction over abduction, and consequently, regards many of the cognitive aspects of reasoning as liabilities. The cognitive view, in stark contrast, candidly acknowledges both the researcher as an active reasoner and the use of abductive reasoning in crucial phases of research (e.g., Hanson, 
1958; Lipton, 2004). It thus questions the positivist pursuit of a single scientific method that defines good scientific practice (Feyerabend, 1993).

\section{Descriptive, Prescriptive and Normative Reasoning Criteria}

If the task is to formulate a view of reasoning where both computational and cognitive elements are acknowledged, how should we revise our methodological criteria? Recent developments in cognitive science offer a useful toolkit for addressing the issue. In what has become known as The Great Rationality Debate (Stanovich, 2011), contradictory accounts explaining the seeming irrationality of human reasoning stem from three different bases or “responses” (Stanovich, 1999). The “panglossian response” holds that human beings are inherently rational and that any observed irrationality is ephemeral. ”The apologetic response” in turn posits that human beings are not inherently rational and importantly, that improving rationality is an unattainable goal; in our ability to reason rationally, we simply are what we are. Finally "the meliorist response” acknowledges that human beings are less than perfectly rational and that perfect computational rationality is unattainable, but at the same time, acknowledges individual differences: some are more rational than others and neither rationality nor irrationality is an essential human condition. The meliorist response is also empirical supported.

The meliorist response resonates with the goals of this paper, because one can think of improving the soundness of our reasoning as the primary objective of methodology. This suggests that sound reasoning involves three separate aspects that all warrant attention. Much of the computational aspect of reasoning is captured by what Stanovich (1999) discusses under the label of normative reasoning. The normative aspect focuses on reasoning under conditions of perfect rationality. The second, descriptive aspect pertains to how we de facto reason and the criteria typically address transparency; the descriptive criterion is met when the author has 
sufficiently illuminated his or her reasoning. The third, prescriptive aspect pertains to the kinds of methodological criteria that should be set for reasoning. The emphasis in the prescriptive aspect is on reasonable and operational criteria: what kinds of reasoning can we expect from researchers whose cognition is appreciably limited?

The prescriptive-normative distinction is critical, firstly, because it avoids the assumption that researchers are able to approach perfect rationality. Secondly, it even researchers were perfectly rational, the norms themselves may be unattainable. It would be misleading, for instance, to presume that improving our inductive reasoning practices brings us closer to solving the problem of induction (Ketokivi \& Mantere, 2010). The problem of induction presents a fundamental dilemma, and dilemmas are by definition not solvable. Prescription can be thought of as setting criteria that can be required from a cognitively limited reasoner, that is, "specifying how processes of belief formation and decision making should be carried out, given the limitations of the human cognitive apparatus and situational constraints [---] with which the decision maker must deal” (Stanovich, 1999: 3).

The meliorist position is particularly useful here, because we can derive three methodological criteria for evaluating the soundness of reasoning: the normative criterion addresses epistemological considerations; the descriptive criterion pertains to transparency; the prescriptive criterion links to methodological rigor (Table 1). Importantly, the prescriptive criterion is not reducible to either of the other two criteria. To reduce it to the descriptive would mean abandonment of methodological rigor in favor whatever practices of reasoning the researcher reports as long as the description is sufficiently transparent. To reduce it to the normative would lead to unduly severe evaluation. 


\section{Insert Table 1 here}

\section{REASONING ACROSS ORGANIZATIONAL RESEARCH}

In this section, we examine reasoning in more detail across organizational research traditions. The objective is to elaborate the descriptive, prescriptive, and normative criteria in the context of deductive, inductive and abductive reasoning. The methodological basis for reasoning stems from proper definition and assignment of these criteria in the given research tradition. As organizational research traditions tend to be heterogeneous in their methodology, we structure the discussion by first distinguish three different research traditions, which in our view account for the majority of organizational research.

In theory-testing research (Bagozzi \& Phillips, 1982; Stinchcombe, 1968), hypotheses are developed from a priori theoretical considerations and testing here means confirming or disconfirming these hypotheses using statistical inference. This research design is adopted from the natural sciences (Hempel, 1965; Popper, 1959; Whewell, 1840), although unlike in the natural sciences, the application of the approaches in organizational research typically involves observational not experimental data.

In inductive case research (Eisenhardt, 1989; Yin, 2003), theory is developed in a datadriven manner from contextual empirical data; some variant of the grounded theory approach (Glaser \& Strauss, 1967) is often used. This tradition is sometimes dubbed "post-positivist" qualitative research (Denzin \& Lincoln, 2005), because it is founded on the idea of a division of labor between qualitative scholars who build new theory through their inductive case studies, and quantitative scholars who test those theories in larger samples (Edmondson \& McManus, 2007; Eisenhardt, 1989). In inductive case research, theory has roughly the same meaning as in theorytesting research: a theory is a set of propositional statements linking the key concepts in the 
theory to one another (e.g., Whetten, 1989). The characteristic outcomes of inductive case research are theoretical propositions to be examined by further theory-testing research. Such division of labor is facilitated by a common set of philosophical assumptions: both theory-testing and inductive case researchers tend to adopt a scientific realist view of studying organizations (Eisenhardt, 1991).

Finally, interpretive research designs (Hatch \& Yanow, 2003) are similar to inductive case studies in that they rely on qualitative data. Interpretive researchers, however, build theory in a manner very different from inductive-case or theory-testing approaches. Interpretive research is carried out as a dialogical process between theory, the empirical phenomenon, where the researcher subject plays a crucial role in performing the interpretation (Gadamer, 1975; Hatch \& Yanow, 2003). This process should not be understood as an instrument towards a "final explanation,” rather, the interpretive process is highlighted as an outcome in and of itself. As a result, interpretive scholarship produces reflexive narratives, not explanatory models or theoretical propositions. Interpretive researchers further tend to use analytical methods different from those used in inductive case study; narrative and discourse analysis are good examples. The interpretive research design in organizational research is founded on the notion that social scientific inquiry should not be modeled after the natural sciences but as an independent tradition (Hatch \& Yanow, 2003; von Wright, 1971).

Methodological organization-scientific literature often links specific types of reasoning to specific research designs: theory-testing is characteristically a "deductive style of research (Rumelt, Schendel, \& Teece, 1991: 8); theory-building based on qualitative data is inductive (Eisenhardt \& Graebner, 2007); interpretive scholarship is abductive (Hatch \& Yanow, 2003). For the most part, these claims have their foundation in the normative criteria for reasoning: that 
theory-testing is described as “deductive research” no doubt links to Hempel’s (1965)

hypothetico-deductivism and Popper's (1959) deductive theory testing. Inductive case study, in turn, is based on the idea of researcher-invariant eliminative (“Baconian”) induction.

The normative criterion is important but not sufficient. A closer look at research practice indeed quickly reveals that all organizational researchers across research traditions and research designs use all three forms in their work: we all make inferences to a case (use deduction), inferences to generalizations (use induction), and inferences to explanations (use abduction). Differences between research approaches, whatever they may be, are found not in the types of reasoning used, but rather, in how the three reasoning types are used in conjunction with one another. The descriptive and the prescriptive criteria in particular must consider this.

Embracing this crucial premise, we analyze in the following the roles and evaluative criteria for deduction, induction and abduction in organizational scholarship. The discussion within each type of reasoning begins with the normative criterion: in discussing deductive reasoning, we thus first discuss its use in theory-testing; in discussing inductive reasoning, we first examine inductive case study; in abduction, we begin with interpretive research.

\section{Evaluating Deductive Reasoning}

The normative criterion for assessing deductive reasoning is logical coherence within a system of statements (Table 2). The principle of logical coherence is straightforward, but complications arise from the fact that organizational theories are expressed in a natural as opposed to a formal language. While formal logic may be applied to a theory to uncover logically invalid inferences, logical coherence must be understood as a normative criterion. The normative criterion of formal explicitness may have appeal in some contexts, but prescription must be approached with caution: “[n]atural language is unparalleled in important respects—no 
formal language approximates its flexibility and expressive power” (Peli, Bruggeman, Masuch, \& Ó Nualláin, 1994: 586). It is impossible to exhaustively explicate in a logically flawless manner all the premises and the conclusions of a theory expressed in a natural language.

Insert Table 2 here

No theory about organizations is logically coherent in the normative sense, yet, we consider them methodologically acceptable. A case in point, a logical analysis of the formal structure of organizational ecology (Hannan \& Freeman, 1984)—logically perhaps the most rigorous organization theory to date-revealed both unnecessary assumptions as well as theorems unsupported by assumptions (Peli et al., 1994). While this has led to a number of further developments and revisions of the theory (Hannan, Pólos, \& Carroll, 2003), the normative criterion of complete logical coherence may never be met. Further, we will demonstrate that logical coherence cannot be promoted as a universal criterion. This calls for formulation of descriptive and prescriptive criteria.

Evaluation of deduction in theory-testing research. Deduction is an indispensable tool for the theory-testing researcher, both in the theoretical and the empirical realm. In the theoretical realm, the idea that theoretical propositions (theorems) follow from the underlying theoretical premises (assumptions) in a deductively valid manner is often considered one of the hallmarks of good theorizing. Indeed, the notion of formal theory connotes precisely such logical tractability of argument (Hannan et al., 2003; Peli et al., 1994). In order for a formal theory to be worth empirical scrutiny, its propositions must be consistent and coherent. In the empirical realm, in turn, all the operations where raw data are transformed into, say, summary statistics are mathematical calculations and thus deductions. 
The normative criterion in assessing deduction in theory-testing studies is the notion that empirical operationalizations and hypotheses must be logically derived from theory; hence the label hypothetico-deductive. If the normative criterion is met, the premises unambiguously imply the conclusion. If the underlying theory is logically coherent and unambiguously implies the hypothesis, then the hypothesis is also logically coherent and consequently, worthy of empirical scrutiny. Logical coherence thus leads to full transparency.

While the philosophy of science literature has provided us with the normative criterion of the method (Hempel, 1965; Whewell, 1840), it has also unequivocally demonstrated that theoretical terms used in scientific theories are not formally reducible to observational statements (e.g., Quine, 1951). This effectively makes the normative criterion an unattainable ideal and consequently, ineffective as a prescriptive criterion. In research practice, we must thus both describe and prescribe our deductive reasoning in other than formal terms, for instance, to establish the correspondence between a theoretical concept and its empirical counterpart (Bagozzi \& Phillips, 1982; Costner, 1969; Keat \& Urry, 1975). This begs the question: if the link between theory and empirical analysis is not deductive in the formal sense, in what sense is the link deductive, or is it deductive at all? What exactly are "the interpretive strings" (Bagozzi \& Phillips, 1982: 461) by which theoretical concepts are translated into derived concepts and subsequently, into empirical concepts? In order to answer these questions in a transparent manner, the researcher must illuminate the underlying logic instead of relying on a rhetorical appeal to deductive reasoning. Illumination must start at the realization that deductive logic is not limited to formal logic such as first-order predicate logic. Instead, a variety of deductive (and other) logics are employed in theoretical arguments that are expressed in a natural language (Mankletow \& Over, 1990). This obviously applies to all organizational research, but in the case 
of the theory-testing tradition, the question pertains to the correspondence between theoretical propositions and empirical hypotheses in particular.

The details of various alternative logics are outside the scope of this paper; we refer to Mankletow and Over (1990) for a concise summary. What is relevant here is the implication to the descriptive and the prescriptive criteria. The central prescriptive criterion here is that as long as natural language is used to express theory, formal validity constitutes a sufficient but not a necessary condition for methodological validity of deductive reasoning. Therefore, the fact that a theory is incoherent in the first-order-logic sense may serve as a normative criterion that illuminates formal logical inconsistencies, but applying this normative criterion as prescriptive requires the dubious assumption that organization theories should adopt formal logic as a universal criterion. Our position is that because such criterion simply cannot be met, it provides a non-operational basis for prescription. Prescription must instead be based on examining how the rules of the selected logic are followed; different logics rely on different kinds of semantic rules, and prescriptive criteria must be based on such local rules. To the extent that these rules are followed, deductive reasoning becomes tractable. Importantly, reasoning is only locally tractable: deductive reasoning does not follow universal but in contrast, highly contextualized forms and norms of reasoning. Unlike the normative criterion, the prescriptive criterion builds on the notion of local epistemology, as discussed by Longino (2002).

Evaluation of deduction in inductive case research. While deduction does not feature in the normative writings on inductive case research, it has a role within the practice of all qualitative research, which makes it relevant from the descriptive and prescriptive points of view. Much like theory-testing scholars, inductive case scholars need deductive reasoning to locate and motivate their research problems among targeted literatures. Research problems can be 
established by showing that the existing literature is incomplete and that there is a gap in the body of knowledge (Alvesson \& Sandberg, 2011); arguing for mixed evidence is common as well (Locke \& Golden-Biddle, 1997; Mohr, 1982). One may even argue that the entire literature has been inappropriate in how the research question has been approached (Alvesson \& Sandberg, 2011; Locke \& Golden-Biddle, 1997). Establishing such positions relies on deductive reasoning; arguing for a gap in the literature is an inference to a case, not to a generalization let alone to an explanation. For this inference to a case to be effective, its premises and the bridge to the conclusion must be elaborated (the descriptive criterion), and established as content valid and coherent by one’s target audience (the prescriptive criterion).

Inductive case researchers also often use not only qualitative but also quantitative data and may thus use mathematical computations in the process of summarizing and making generalizations from data. Content-analytical techniques of generalizing, in turn, form large textual masses and may involve the quantification of the data, followed by deductive operations that range from simple computation of frequencies (e.g., Mantere, 2005) to more complicated multivariate statistical analyses (e.g., Gibson \& Zellmer-Bruhn, 2001). Here, descriptive and prescriptive criteria converge with those applicable to mathematical computations within the domain of theory-testing research.

Evaluation of deduction in interpretive research. Methodological literature on the interpretive research design is silent on deduction. Yet, while the cognitive act of interpretation is largely abductive as multiple interpretations are explored in parallel (Alvesson \& Kärreman, 2007), deduction plays a key role in structuring and presenting interpretive findings. Interpretations of data are effectively presented as deductive chains, starting at a general principle which is then illustrated with examples from the source text. For instance, scholars 
using deconstruction (e.g., Boje, 1991; Kilduff, 1993; Martin, 1990) begin the presentation of their interpretation with a provocative general claim, followed by an example from the source text, which is then shown to be logically implied by the generic statement.

Descriptive evaluation of deduction centers on the transparency of the deductive chains. An overall prescriptive principle for evaluating interpretive scholarship is narrative coherence, that is, the credibility and plausibility of the theoretical story presented (Czarniawska, 1993; Fisher, 1985). Prescriptive evaluation is focused on whether the story "hangs together" in terms of the logical aspects of the plot (Fisher, 1987: 15). In particular, deduction is used to achieve structural coherence (Fisher, 1987: 13), which constitutes a crucial aspect of narrative coherence.

\section{Evaluating Inductive Reasoning}

Conventionally, the normative criterion for inductive reasoning is researcher invariance: an inductive generalization should result in the same generalization regardless of the reasoner (Eisenhardt, 1989). This arises from the normative premise that induction is about rule-following: computation, not cognition. The normative view is straightforward in principle, but complications arise from two sources. One, theory-building practice is not and cannot be researcher invariant. Prescribing that researchers should somehow "abstract themselves out” of the reasoning process may be normatively appealing but is prescriptively unattainable (Ketokivi \& Mantere, 2010). The second problem is epistemological: the philosophy of science literature on the link between empirical data and theoretical explanation has consistently argued that theoretical explanations simply cannot emerge from empirical data in a computational, objective manner (e.g., Carnap, 1952). Table 3 summarizes inductive reasoning.

Insert Table 3 here 
Evaluation of induction in inductive case research. Inductive case study derives from the tradition of grounded-theory research, which is succinctly characterized as systematic discovery of theory from data, with less emphasis on a priori theoretical considerations (Glaser \& Strauss, 1967). Eisenhardt's (1989) formulation of inductive multiple case study research has been widely adopted in organizational research as the model of case research. As the label suggests, induction is the tool for trade implied by the normative inductive case tradition. The normative criterion for evaluating induction within this tradition is the elimination of researcher interpretation from the generalizations drawn from the data. One of the central premises in inductive case research is the idea that the researcher can gain theoretical insight from data by using inductive reasoning in research phases such as iterative tabulation, cross-case pattern search, and replication (Eisenhardt, 1989: 533). Such tendencies embedded in the data—not the interpretations of the researcher—are seen as the "raw material" for reasoning.

The caveat of the normative criterion is that one cannot in practice reach a theoretical conclusion from empirical observation by inductive generalization (Carnap, 1952; Peirce, 1877; Popper, 1959); theorizing calls for inferences to explanations, not just to generalizations (Suddaby, 2006; Sutton \& Staw, 1995); explanation thus involves abduction. While the normative ideal can provide an inspiration for rigor and authenticity in one's approach to the data (Eisenhardt \& Graebner, 2007), much like with deduction, the prescriptive criterion cannot be collapsed into the normative.

The prescriptive criterion is founded on impartiality in interpretation, and it is applicable to those phases of the research process where empirical generalizations are made. Specifically, computational induction is particularly important in the early coding of textual data, which involves the classification of specific segments of text into more general categories (Strauss \& 
Corbin, 1990). Identifying a segment of text as a member of a particular category is inductive as it leads, by supporting generic categories with particular instances, to the affirmation of a more general empirical tendency.

Induction is thus most relevant in those stages of the coding process where the researcher's generalizations are predominantly empirical; these tend to be the earlier stages in the process of coding. In their impactful treatise on grounded coding, Strauss and Corbin (1990) proposed that a grounded analysis begins with microanalysis, where the text is read with an open mind, identifying passages that appear particularly noteworthy or relevant to the research problem at hand. Microanalysis is followed by open coding, where a large set of empirical categories is established. In both microanalysis and open coding, researchers identify empirical tendencies in the data. The focus in this process is primarily on enumerative induction.

The descriptive criterion for induction is the transparency of empirical generalizations. Illustrations from data through quotations and extracts are effective tools to this end. Prescriptive evaluation is founded on unbiased generalization by the researcher. While this is often achieved by a careful explication of coding principles, external audits of various kinds are sometimes used further reinforce a sense of unbiased generalization (cf. Corley \& Gioia, 2004). Interrater reliability tests are sometimes used to check whether a number of coders have identified the same instances in the empirical texts (microanalysis), and whether they used the same codes to categorize these instances (open coding) (e.g., Gibson \& Zellmer-Bruhn, 2001).

Evaluation of induction in interpretive research. Induction does not have the same computational role in the analysis practice of interpretive scholars as it does in the work of inductive case scholars. Rather than focus on general empirical tendencies of their data, interpretive scholars center on striking and idiosyncratic examples, and use these as clues in 
solving a mystery (Alvesson \& Kärreman, 2007). Elaborate coding frameworks are rarely used; rather than starting data analysis with extensive open coding, interpretive scholars begin with a "pre-understanding” which they then use to start their "dialogue with the data” (Gadamer, 1975). Interpretive scholars do, however, use analogical reasoning. A special case of induction (Walton, 1989), analogical reasoning is used to interpret one entity based on similarity with another entity (Cornelissen \& Clarke, 2010; Oswick, Keenoy, \& Grant, 2002). Rather than inferring general principles from particulars, analogical reasoning uses particular similarities in two cases to infer further similarities (Hesse, 2000). The widespread use of analogical reasoning likely links to the common use of metaphors in interpretive theorizing (Boje, 2008; Czarniawska, 1993; Morgan, 2006). With analogical reasoning, researchers may draw on the power of metaphor and use a simple, more contained case to illuminate an aspect of the focal case (Lakoff \& Johnson, 1980). For instance, in his deconstruction of the Disney Corporation, Boje (1995) used the Hollywood play Tamara as a basis of theorizing. Boje first argued for the similarity between the play and an organization and subsequently, used Tamara's properties to illuminate various aspects of organization: "The beauty of Tamara is that the choices surrendered by singlestory interpretations of organization are returned in this discursive metaphor for organizational life” (Boje, 1995: 1001). The analogical case may also be used to recontextualize the focal case. In their deconstruction of leadership, Calás \& Smircich (1991) contrast passages of classical leadership texts with various texts about seduction. The goal was to reveal the surprising, even shocking resemblance between the two textual domains. The descriptive and prescriptive criteria for analogical reasoning involve the transparency and credibility in arguing for similarities between two domains. 
Evaluation of induction in theory-testing research. In theory-testing research, the normative criterion is unambiguous: inductive reasoning is not acceptable. This point was forcefully argued by Popper (1959), who formulated his method of deductive theory testing as an express attempt to banish inductive reasoning from theory testing. The aim is noble, but at the same time, this constitutes perhaps the best example of the unattainability of the normative criterion. Indeed, we cannot think of a single organization theory that has been falsified in a deductively valid manner; in fact, we are not even aware of any genuine attempts at falsification. Hajék and Hall’s (2002: 154) candid description of the utility of Popper's method for describing or prescribing research practice is as accurate as it is unflattering: “As a descriptive claim about what scientists, qua scientists, actually do-let alone about what they believe about what they do-Popper's view strikes us as absurd. But even as a [prescriptive] claim it fares little better.” All claims to falsification in organization-scientific texts must be understood and evaluated as rhetorical, not methodological (Ketokivi \& Mantere, 2010).

Salmon (1966: 19), among others, has reminded that inferences made from empirical data are never deductive: they are either inductive (in the case of inferences to empirical generalizations) or abductive (in the case of inferences to theoretical explanations). Indeed, induction unavoidably underlies all empirical generalizations made in theory-testing research. But if Popper's normative criterion is non-operational, what are proper descriptive and prescriptive criteria? Workable descriptive criteria for an inductive statistical generalizations can be found in many statistical texts that discuss statistical hypothesis testing, effect sizes, statistical power, and articulation of results (Abelson, 1995; Harlow, Mulaik, \& Steiger, 1997); it is hardly necessary to reproduce these well-established criteria here. We will instead focus on discussing theory appraisal more generally. 
Empirical hypotheses in organizational research are typically examined through probabilities and tendencies instead of "if-then" -type certainties. This is another crucial reason for why the prescriptive criterion for inductive reasoning is impossible to link to Popper's normative idea of falsification: what kind of evidence could falsify—in a deductively valid manner - the proposition "if X increases then Y likely increases as well”? Prescriptive criteria can, however, be formulated on the basis of empirical adequacy (van Fraassen, 1980) and positive relevance (Salmon, 1966). Both address the extent to which the theory provides an account for the observed data. Indeed, most applications of multivariate statistical modeling examine not whether the data are consistent with the theory, but rather, the extent to which this is the case; the greater the extent, the greater the degree of empirical adequacy. As empirical adequacy accumulates through multiple empirical studies, the focal theory accumulates positive (inductive) relevance. The prescriptive criterion thus links to the rigor in which empirical adequacy and positive relevance are discussed.

\section{Evaluating Abductive Reasoning}

The normative ideal of abduction in philosophical discourse (Harman, 1965; Lipton, 2004; Niiniluoto, 1999; van Fraassen, 1980) is the selection of "the best explanation" among competing ones. This selection process is always fundamentally cognitive, not computational. In the multi-paradigmatic field of organizational research, criteria for what constitutes "the best" further often conflict with one another, and are further subject to negotiation between the authors and their audiences (Ketokivi \& Mantere, 2010). Consequently, much like in the case of deductive and inductive reasoning, the normative ideal is non-operational and insufficient, and descriptive and prescriptive criteria must be formulated. Descriptive evaluation of abduction is founded on the transparency of the main explanations considered, whereas prescriptive 
evaluation places an expectation of compliance to local epistemic values in selecting the explanation. Table 4 summarizes abductive reasoning.

Insert Table 4 here

Evaluation of abduction in interpretive research. Interpretive scholars (Alvesson \& Kärreman, 2007; Locke et al., 2008; Wodak, 2004) in particular not only accept but also openly acknowledge cognitive reasoning as legitimate methodology. Many interpretive scholars regard as their methodological foundation the hermeneutical circle, which depicts understanding as continuous dialogue between the focal text and the interpreter's pre-understanding. Consequently, interpreting a text is portrayed by methodological authorities as a characteristically abductive exercise (Eco, 1984; Wodak \& Meyer, 2009). Interpretive scholars further openly admit that preunderstanding is always informed by existing theories (Gadamer, 1975), and thus, abduction is a process driven by the interplay of doubt and belief, which in turn fuels the imaginative act of creating new knowledge (Peirce, 1878). The principle has been discussed in organizational research by Locke, Golden-Biddle \& Feldman (2008) and Van de Ven \& Johnson (2006), among others. In her account of critical discourse analysis, Wodak (2004), for instance, suggested that critical discourse analysis is an "abductive approach, [which requires] a constant movement back and forth between theory and empirical data." She further argued that the abductive approach is an antidote against "fitting the data to illustrate theory" (Wodak, 2004: 200). Similarly, Boje (2001: 51-52) suggests that for the narrative analyst abduction represents "an ongoing inquiry where scientists have a more spontaneous creative insight they speculate may be tied to their data, or they select one among several plausible hypotheses.” 
Interpretive researchers write reflexive narratives where their pre-understandings meet with the text as "the other," allowing them to contribute to a new understanding of theory through the evolution of their own understanding of the text. Encounters with data involve a dynamic of the data being interpreted in light of theory, but importantly, interpretive researchers must remain open to be challenged by the data by continually calling into question their own preunderstanding (Alvesson \& Kärreman, 2007). Maintaining this reciprocity is a central concern: if the researcher does not remain open to "being surprised" by the data, reasoning deteriorates from disciplined abduction to methodologically void rhetoric, where the conclusion merely reflects the researcher’s pre-understanding (Alvesson \& Kärreman, 2007; Wodak, 2004).

Interpretive scholarship is methodologically founded on the cognitive view; the normative and the prescriptive criteria thus converge. The concept of reflexivity (Alvesson \& Sköldberg, 2000) provides the foundation for the evaluation of abduction in interpretive research, in all three senses. Reflexivity entails the revealing and assessment of the subjective criteria for interpretive choices. It sets the foundation for descriptive evaluation, where interpretive choices are exposed to scrutiny, as well as prescriptive evaluation, where the credibility of interpretations is assessed. The practice of interpretive research differs from other forms by openly revealing the subjective and imaginative element of abduction. In his deconstruction of Disney, Boje (1995: 1006-1007) used multiple paragraphs reflecting on the various types of deconstructing a text as well as on his choice of a specific type. In their study of the Big Five accountancy firms, Suddaby \& Greenwood (2005: 46) recounted how they discovered a key theoretical category during an informal discussion with a colleague from religious studies.

Evaluation of abduction in theory-testing research. Much like in the case of inductive reasoning, normative methodology rejects abductive reasoning: as a special case of the fallacy of 
affirming the consequent, its use cannot be methodologically justified. At a more general level, Popper (1959: 31) argued that the discovery of hypotheses does not belong to the domain of methodology: "The question how it happens that a new idea occurs to a man... is irrelevant to the logical analysis of scientific knowledge.” But again, we must bear in mind that limiting the appraisal of scientific reasoning to logical analysis can be justified only in the normative sense. Other criteria must be developed for the descriptive and the prescriptive aspects.

How does one justify the R\&D-to-sales ratio (R\&D intensity) as a measure of innovativeness, Return on Assets as a measure of financial performance, or the natural logarithm of the number of employees as a measure of size? The derivation of the R\&D-intensity measure from the theoretical definition of innovativeness is not an argument to a case or to a generalization, it is an interpretation (Bagozzi \& Phillips, 1982). This interpretation is best understood as an inference to an explanation, that is, an abduction (Willer \& Webster, 1970: 754). This makes abduction an indispensable form of reasoning in theory-testing research as well.

Consider a firm with a high R\&D intensity. This surprising observation is made matter of course by abducing the explanation that the firm is innovative. Obviously, there can be many reasons for observing a high R\&D intensity, but the abduction of an innovative firm is not only plausible, it is treated in the literature as methodologically acceptable to boot. Conversely, while a zero R\&D intensity does not universally indicate absence of innovation (Berger, 2005: 152153), such abduction has again proven to be generally plausible and acceptable.

The second principal use of abduction involves the drawing of theoretical conclusions from empirical data. Even in the case of a priori theory, the interpretation of evidence is always an inference to an explanation (abduction). That the link is abductive (not deductive or inductive) helps understand why observing an hypothesis to be consistent with data does not rule out 
alternative hypotheses, it only signals empirical adequacy of the focal theory; the empirical observation "finds a home" in the structure of the focal theory. But the very same observation can "find a home" in other theoretical structures as well. Carter and Hodgson (2006) pointed out that many empirical studies pegged as evidence for transaction cost economics (e.g., Williamson, 1985) are consistent with predictions from other, even competing theories. The problem is further exacerbated by the fact that the requirements for consistency empirical adequacy are quite lenient in the social sciences: theories are typically not expected to predict the magnitude of an effect, only whether the effect is positive or negative (Meehl, 1990).

Current theory-testing methods are poor tools for ruling out alternative explanations (Salmon, 1971); their primary use is in testing the predictions of a single focal theory against empirical data. The focus is thus not on whether one theory explains the data better than another. Some organizational scholars have promoted strong inference, where the focal theory is explicitly tested against another candidate theory using "the crucial experiment” (Platt, 1964: 347). But again, we are not aware of a single rigorous organization-scientific application of strong inference, which leads us to conclude that strong inference can at best be incorporated as a normative criterion.

The descriptive criterion again pertains to transparency. Here, we have an abundance of examples of theory-testing research where researchers have made their choice of operationalizations of theoretical concepts explicit. Consider the choice of the dependent performance variable in Hitt, Hoskisson \& Kim's (1997: 778) study of corporate diversification. Three alternatives were considered, but ROA was chosen on both conceptual and empirical grounds. At the more general level, explicitly discussing alternatives and justifying one's choice—in short, contextualization—makes one's abductions transparent. 
From the idea of contextualization, one can also derive prescriptive implications. While many contemporary prescriptions emphasize universality and generalizability, we derive the prescription from the importance of considering local conditions and idiosyncrasy. Using a given measure of, say, performance simply because it is widely used is a rhetorical appeal to popularity and as such, not acceptable methodology. Instead, the researcher must present the contextual considerations — by way of abductions, for instance—that make the selection matter of course.

Evaluation of abduction in inductive case research. Abduction is not covered in normative literature around inductive case research. Instead, methodological literature suggests that theoretical propositions emerge inductively from the data (Eisenhardt, 1989). In research practice, however, identification of empirical tendencies by induction is a crucial but only one part of an inductive case study. Theories are constructed, and abduction is used in seeking theoretical interpretations for the observed empirical tendencies and in choosing between possible theoretical interpretations. In Strauss \& Corbin’s (1990) framework, the two predominantly inductive stages—-microanalysis and open coding—are followed by two theoretical stages: axial coding and selective coding. In axial coding, the researcher creates a hierarchy of categories, which consists of a large number of empirical, first-order codes that fall under a more limited set of theoretical dimensions (cf. Corley \& Gioia, 2004). Selective coding, in turn, involves a further focusing of the set of categories through the identification of relationships between key theoretical entities.

Descriptive evaluation pertains to disclosing the abductive nature of the axial and selective coding stages. Instead of suggesting that theoretical constructs and propositions existed in the data a priori, the cognitive role of the researcher in the creation of such entities must be made. Glaser \& Strauss (1967: 251, italics supplied) noted that “[t]he root sources of all 
significant theorizing is the sensitive insights of the observer himself... [insights] can come in the morning or at night, suddenly or with slow dawning, while at work or at play (even when asleep)... they can strike the observer while he is watching himself react as well as when he is observing others in action.” Reflexivity is a key consideration not only in interpretive analyses of qualitative data but also in inductive case research. Prescriptive evaluation is focused on the credibility of this selection, weighed against the epistemic values of the scholarly community.

\section{DISCUSSION}

Normative, prescriptive and descriptive modes of evaluation all contribute to the process of robust knowledge creation, but have different roles. The normative criterion pertains to epistemological rigor, the descriptive criterion to transparency, and the prescriptive criterion to methodological rigor. These roles must not be confused with one another: using a normative criterion as prescriptive, for instance, leads to unduly harsh evaluation and epistemological pitfalls. We will discuss the implications of our analysis in the following.

\section{Epistemic Rigor through Normative Evaluation}

The normative aspects of methodology tend to trace back to the philosophy of science. The core of this enterprise is the discovery of universal principles that characterize knowledge creation across sub-disciplines. But using this body of knowledge as a basis for prescription is problematic in two ways. First, there is roughly as little agreement among philosophers of science on the exact nature of scientific reasoning as there is agreement among strategy scholars on the sources of competitive advantage. Second, while the literature on philosophy of science is a rich source of insight, it is a poor source of practical guidelines.

Normative evaluation is, however, central in setting the boundaries on the certainty of knowledge produced. Organizational scholars can certainly benefit from understanding the noble 
aims of logical positivism and the central reasons for its demise, as discussed by Quine (1951); we can all gain from understanding Feyerabend's (1993) methodological critique and the rationale behind his famous claim that the society must "be defended against science." At the same time, reading Popper’s (1959) Logic of Scientific Discovery or Feyerabend's (1993) Against Method as handbooks for research practice will only lead to confusion, frustration, and in the worst case, methodologically hypocritical rhetoric. Normative philosophical texts address philosophical problems, they are not meant to legislate research practice (Carnap, 1984;

Friedman, 1991). We suspect that not a single answer to the practical challenges of an empirical organization scientist can be found in these texts, which is only to be expected; unless one is intimately familiar with the field, how could one even know what these challenges are, let alone provide methodological guidance on how to meet these challenges?

The role of normative evaluation is to maintain epistemological rigor in our work. Epistemic rigor is best described as resilience and restraint that stems from appreciating the unavoidable incompleteness of our knowledge claims. It helps us understand why hypotheses can never be verified, why hypothetico-deductivism offers a poor method for ruling out alternative explanations, and how all empirical research is haunted by epistemological dilemmas that arise from the problem of induction. In research practice, however, there is not much the researcher can do methodologically about trying to solve these dilemmas; the normative does not translate to the prescriptive.

\section{Transparency through Descriptive Evaluation}

Reasoning is always in part idiosyncratic and contextual, which makes descriptive evaluation of reasoning crucial. Elucidating one's choices strengthens credibility. The call for transparency calls for the disclosure of cognition in all its idiosyncrasy: personal insights, 
serendipity, imperfections, and novel ways of interpreting data. After all, in appraising a manuscript for its merits, is it not in many ways more central to evaluate how exactly the author reached the specific conclusions_-"how they came to know?”- than what exactly the specific conclusions were-“what they know?” (cf. Van de Ven \& Johnson, 2006)?

If reasoning were simply a matter of computation, transparency would follow automatically: all we would have to do is to provide an inventory of the computational rules followed. Better yet, if this inventory were already formalized in the literature, one could simply supply the citation. Implicit reliance on the idea that reasoning principles exist formalized and $a$ priori links to the observation that many organization-scientific texts read as if the researcher did not make any choices; instead, unobservable constructs seem to unambiguously translate into empirical measures and theoretical propositions into observational hypotheses. One gets the impression that the task of the scientist in the process was to follow a predetermined set of rules which, properly applied, inevitably led the authors to their conclusions. The computational aspects of reasoning are accentuated, cognitive aspects disregarded.

But the cognitive aspects are just as material as the computational. One of the primary tasks of those who evaluate an argument is to understand how the researcher reasoned from the premises to the conclusions. Understanding merely the computational aspects of this process leads to a seriously amputated understanding, in particular with regard to how the theoretical explanations and interpretations were constructed.

\section{Methodological Rigor through Prescriptive Evaluation}

Taking our analysis to its obvious yet provocative conclusion, we challenge the classical conception of science that highlights computational reasoning and seeks a universal foundation for methodology. We argue instead that the more we rely on normative models such as Popper's 
deductive theory testing in our arguments, the less methodologically credible our work tends to become. Suddaby's (2006) critique of superficial rhetorical appeals to grounded theory in organization-scientific qualitative texts echoes a more general methodological concern: the common assumption that normative models are methodologically sufficient to illuminate scientific practice is empirically false (Kaplan, 1964).

Prescriptive evaluation plays a crucial role in the process where the credibility of knowledge claims is assessed (Patton, 2002). The process is about methodology, but it is a local, social process of a scholarly community, where methodological rigor is based on local rules that stem from contextual methodological considerations and preferences (Patton, 2002). These rules are constantly negotiated and renegotiated through various processes of evaluation: doctoral defenses, manuscript review processes, seminars, and other scholarly meetings. In contrast with normative evaluation, prescriptive evaluation does not afford a priori authority to any methodological principle. Symmetrically, prescriptive preferences have no authority beyond the community that has granted them.

Deduction is a good example: while formal first-order predicate logic can be universally applied to scrutinize just about any organization theory for logical consistency, the validity of its application requires contextual scrutiny. Organization ecologists have found a basis for such validity, but no other organization theory comes to mind where application of first-order predicate logic has led to appreciable theory improvement. Whether other applications are fruitful is to be settled in future research. However, because the subject matter of many organization theories is not formal but empirical in its essence (e.g., Corley \& Gioia, 2011; Glaser \& Strauss, 1967), the examination of merely logical connections between premises and conclusions constitutes at best an incomplete, and at worst, a misguided exercise. 


\section{CONCLUDING REMARKS}

Why do we acknowledge that managers reason with limited and biased cognitions, but at the same time, promote methodological principles that are erected on the assumption of researcher-invariant and objective rationality? Churchland \& Schainblatt (1965: 70) noted the unsettling consequence: "Some scientists believe that because they think clearly and rationally in their own disciplines they are particularly adept at thinking clearly and rationally about almost any important decision problem. Many managers are shocked by the claim that scientists can penetrate the extreme subtleties of managerial decision-making in sufficient depth to accomplish anything but the superficial.”

Organization scientists are no less human than managers. In light of this, how should we orient ourselves toward the contemporary notion of evidence-based management, which, according to Pfeffer and Sutton (2006: 3), “every company needs”? If managers act on knowledge and academics have the opportunity to participate in its construction, what is the proper role for us? Perhaps we should not think of evidence as a compilation of facts to which we-by the virtue of being scientists—are somehow privileged. The chances are the practitioner is already much more familiar than us with the relevant facts: "Most of what matters is captured in the particularistic features of the organizations. In most cases managers who want advice would find it better from themselves or their associates than from a consultant or a research study" (March, 1999: 331).

Embracing March’s sentiment, we suggest redefining evidence as a process_- “how we come to know?”- that incorporates intellectual rigor in all its forms: normative, methodological, and descriptive. Paying attention to all three ensures that arguments are maximally transparent (the descriptive criterion), locally rigorous (the methodological criterion), and openly admit that 
evidence-based arguments emanating from the academic community are not privileged with certainty or objectivity (the epistemological criterion). In contrast to what we might think, gathering evidence may do little to remove ambiguity and uncertainty from any non-trivial decision situation. The normative aspect in particular reminds us that the problems we face in knowledge generation are dilemmas, and much like in the case of managerial dilemmas (e.g., Miller, 1992), all prescription must start at acknowledging that the proper way to cope with dilemmas is not to try to solve them but rather, to make an informed and transparent choice. Moving toward sound reasoning requires the assignment of proper roles for normative, descriptive, and prescriptive aspects of reasoning. Considering all three leads to a set of criteria that are comprehensive, reasonable, and operational at the grassroots of organizational scholarship. Most importantly, the construction of these criteria—-the descriptive and the prescriptive in particular-is a local task. We may turn to the philosopher or other authorities outside our own fields of inquiry for normative insight and reflection, but we must regulate our scientific practices locally. Whatever prescription follows should pay heed to Mintzberg's (1977: 91) counsel: avoid giving prescription about how something should be done until you have carefully studied how it is currently done and why. 


\section{REFERENCES}

Abelson, R. P. 1995. Statistics as Principled Argument. Hillsdale, N.J.: Lawrence Erlbaum Associates.

Alvesson, M., \& Sköldberg, K. 2000. Reflexive Methodology, New Vistas for Qualitative Research. London: Sage Publications.

Alvesson, M., \& Kärreman, D. 2007. Constructing mystery: Empirical matters in theory development. Academy of Management Review, 32: 1265-1281.

Alvesson, M., \& Sandberg, J. 2011. Generating research questions through problematization. Academy of Management Review, 36: 247-271.

Astley, W. G. 1985. Administrative science as socially constructed truth. Administrative Science Quarterly, 30: 497-513.

Bagozzi, R. P., \& Phillips, L. W. 1982. Representing and testing organizational theories: A holistic construal. Administrative Science Quarterly, 27: 459-490.

Barker, S. F. 1957. Induction and Hypothesis. Ithaca, NY: Cornell University Press.

Bazerman, M. 2002. Judgment in Managerial Decision Making (5th ed.). New York: Wiley.

Bell, D., Raiffa, H., \& Tversky, A. (Eds.). 1989. Decision making: Descriptive, normative, and prescriptive interactions. Cambridge: Cambridge University Press.

Berger, S. 2005. How We Compete. New York: Doubleday.

Boje, D. M. 1991. The storytelling organization: A study of story performance in an officesupply firm. Administrative Science Quarterly, 36: 106-126.

Boje, D. M. 1995. Stories of the storytelling organization: A postmodern analysis of Disney as 'Tamara-Land'. Academy of Management Journal, 38: 997-1035. 
Boje, D. M. 2001. Narrative Methods for Organizational and Communication Research. London: Sage.

Boje, D. M. 2008. Storytelling Organizations. London: Sage.

Boylan, T. A., \& O'Gorman, P. F. 1995. Beyond Rhetoric and Realism in Economics: Towards a Reformulation of Economic Methodology. London: Routledge.

Brown, S. L., \& Eisenhardt, K. M. 1997. The art of continuous change: Linking complexity theory and time-paced evolution in relentlessly shifting organizations. Administrative Science Quarterly, 42: 1-34.

Calás, M. B., \& Smircich, L. 1991. Voicing seduction to silence leadership. Organization Studies, 12: 567-802.

Carnap, R. 1952. The Cognition of Inductive Methods. Chicago: University of Chicago Press.

Carnap, R. 1984. On the character of philosophic problems. Philosophy of Science, 51: 5-19.

Carter, R., \& Hodgson, G. M. 2006. The impact of empirical tests of transaction cost economics on the debate on the nature of the firm. Strategic Management Journal, 27: 461-476.

Churchman, C. W., \& Schainblatt, A. H. 1965. The researcher and the manager: A dialectic of implementation. Management Science (Series B), 11: B69-B87.

Corley, K. G., \& Gioia, D. A. 2004. Identity ambiguity and change in the wake of a corporate spin-off. Administrative Science Quarterly, 49: 173-208.

Corley, K. G., \& Gioia, D. A. 2011. Building theory about theory building: What constitutes a theoretical contribution? Academy of Management Review, 36: 12-32.

Cornelissen, J. P., \& Clarke, J. S. 2010. Imagining and rationalizing opportunities: Inductive reasoning and the creation and justification of new ventures. Academy of Management Review, 35: 539-557. 
Costner, H. L. 1969. Theory, deduction, and rules of correspondence. American Journal of Sociology, 75: 245-263.

Czarniawska, B. 1993. Writing Management: Organization Theory as a Literary Genre. Oxford: Oxford University Press.

Denzin, N. K., \& Lincoln, Y. S. (Eds.). 2005. The Sage Handbook of Qualitative Research (3rd ed.). London: Sage.

Eco, U. 1984. The Role of the Reader: Explorations in the Semiotics of Text. Bloomington, IN: Indiana University Press.

Edmondson, A. C., \& McManus, S. E. 2007. Methodological fit in management field research. Academy of Management Review, 32: 1155-1179.

Eisenhardt, K. M. 1989. Building theories from case study research. Academy of Management Review, 14: 532-550.

Eisenhardt, K. M. 1991. Better stories and better constructs: The case for rigor and comparative logic. Academy of Management Review, 16: 620-627.

Eisenhardt, K. M., \& Zbaracki, M. J. 1992. Strategic decision making. Strategic Management Journal, 13: 17-37.

Eisenhardt, K. M., \& Graebner, M. E. 2007. Theory building from cases: Opportunities and challenges. Academy of Management Journal, 50: 25-32.

Faust, D. 1984. The Limits of Scientific Reasoning. Minneapolis: University of Minnesota Press. Feyerabend, P. 1993. Against Method (3rd ed.). London: Verso.

Fisher, W. R. 1985. The narrative paradigm: An elaboration. Communication Monographs, 52: 347-367. 
Fisher, W. R. 1987. Technical logic, rhetorical logic, and narrative rationality. Argumentation, 1: $3-21$.

Fodor, J. A. 2001. The Mind Doesn't Work That Way: The Scope and Limits of Computational Psychology. Cambridge, MA: MIT Press.

Friedman, M. 1991. The re-evaluation of logical positivism. Journal of Philosophy, 88: 505-519.

Gadamer, H. 1975. Truth and Method. New York: Seabury Press.

Gibson, C. B., \& Zellmer-Bruhn, M. E. 2001. Metaphors and meaning: An intercultural analysis of the concept of teamwork. Administrative Science Quarterly, 46: 274-303.

Glaser, B. G., \& Strauss, A. L. 1967. The Discovery of Grounded Theory: Strategies for Qualitative Research. Hawthorne, NY: Aldine de Gruyter.

Godfrey, P. C., \& Hill, C. W. L. 1995. The problem of unobservables in strategic management research. Strategic Management Journal, 16: 519-533.

Green, S. 2004. A rhetorical theory of diffusion. Academy of Management Review, 29: 653-669.

Green, S., Li, Y., \& Nohria, N. 2009. Suspended in self-spun webs of significance: A rhetorical model of institutionalization and institutionally embedded agency. Academy of Management Review, 52: 11-36.

Hájek, A., \& Hall, N. 2002. Induction and probability. In P. Machamer \& M. Silberstein (Eds.), The Blackwell Guide to the Philosophy of Science: 149-172. Malden, MA: Blackwell Publishing.

Hannan, M. T., \& Freeman, J. 1984. Structural inertia and organizational change. American Sociological Review, 49: 149-164.

Hannan, M. T., Pólos, L., \& Carroll, G. R. 2003. Cascading organizational change. Organization Science, 14: 463-482. 
Hanson, N. R. 1958. Patterns of Discovery: An Inquiry into the Conceptual Foundations of Science. Cambridge: Cambridge University Press.

Harlow, L. L., Mulaik, S. A., \& Steiger, J. H. (Eds.). 1997. What If There Were No Significance Tests? Mahwah, N.J.: Lawrence Erlbaum Associates.

Harman, G. H. 1965. The inference to the best explanation. Philosophical Review, 74: 88-95.

Hartshorne, C., \& Weiss, P. (Eds.). 1934. Collected Papers of Charles Sanders Peirce, Volumes V and VI. Cambridge, MA: Harvard University Press.

Hatch, M. J., \& Yanow, D. 2003. Organization theory as an interpretive science. In H. Tsoukas \& C. Knudsen (Eds.), The Oxford Handbook of Organization Theory: 63-87. Oxford: Oxford University Press.

Hempel, C. G. 1965. Aspects of Scientific Explanation and Other Essays in the Philosophy of Science. New York: Free Press.

Hesse, M. 2000. Models and analogies. In W. H. Newton-Smith (Ed.), A Companion to the Philosophy of Science: 299-307. Malden, MA: Blackwell Publishing.

Hitt, M. A., Hoskisson, R. E., \& Kim, H. 1997. International diversification: Effects on innovation and firm performance in product-diversified firms. Academy of Management Journal, 40: 767-798.

Josephson, J. R., \& Josephson, S. G. (Eds.). 1996. Abductive Inference: Computation, Philosophy, Technology: Cambridge University Press.

Kahneman, D., Slovic, P., \& Tversky, A. 1982. Judgment under uncertainty: Heuristics and Biases. New York: Cambridge University Press.

Kaplan, A. 1964. The Conduct of Inquiry. San Francisco: Chandler Publishing Company. Keat, R., \& Urry, J. 1975. Social Theory as Science. London: Routledge \& Kegan Paul. 
Ketokivi, M., \& Mantere, S. 2010. Two strategies for inductive reasoning in organizational research. Academy of Management Review, 35: 315-333.

Kilduff, M. 1993. Deconstructing organizations. Academy of Management Review, 18: 13-31.

Lakatos, I. 1970. Falsification and the methodology of scientific research programmes. In I. Lakatos \& A. Musgrave (Eds.), Criticism and the Growth of Knowledge: 91-196. Cambridge: Cambridge University Press.

Lakoff, G., \& Johnson, M. 1980. Metaphors We Live By. Chicago: University of Chicago Press. Lipton, P. 2004. Inference to the Best Explanation. London: Routledge.

Locke, K., \& Golden-Biddle, K. 1997. Constructing opportunities for contribution: Structuring intertextual coherence and "problematizing" in organizational studies. Academy of Management Journal, 40: 1023-1062.

Locke, K., Golden-Biddle, K., \& Feldman, M. 2008. Making doubt generative: Rethinking the role of doubt in the research process. Organization Science, 19: 907-918.

Longino, H. E. 2002. The Fate of Knowledge. Princeton, N. J.: Princeton University Press.

Lycan, W. G. 1988. Judgment and Justification. Cambridge: Cambridge University Press.

Mankletow, K. I., \& Over, D. E. 1990. Inference and Understanding: A Philosophical and Psychological Perspective. London: Routledge.

Mantere, S. 2005. Strategic practices as enablers and disablers of championing activity. Strategic Organization, 3: 157-184.

March, J. G. 1994. A Primer on Decision Making: How Decisions Happen. New York: Free Press.

March, J. G. 1999. The Pursuit of Organizational Intelligence. Malden, MA: Blackwell Publishers. 
Martin, J. 1990. Deconstructing organizational taboos: The suppression of gender conflict in organizations. Organization Science, 1: 339-359.

McCloskey, D. N. 1998. The Rhetoric of Economics (2nd ed.). Madison, WI: University of Wisconsin Press.

Meehl, P. E. 1990. Appraising and amending theories: The strategy of Lakatosian defense and two principles that warrant it. Psychological Inquiry, 1: 108-141.

Miller, G. J. 1992. Managerial Dilemmas. Cambridge: Cambridge University Press.

Mintzberg, H. 1977. Policy as a field of management theory. Academy of Management Review, 2: 88-103.

Mintzberg, H. 2005. Developing theory about the development of theory. In K. G. Smith \& M. A. Hitt (Eds.), Great Minds in Management: The Process of Theory Development: 355-372.

Mohr, L. B. 1982. Explaining Organizational Behavior. San Francisco, CA: Jossey-Bass.

Moldoveanu, M. C., \& Baum, J. A. C. 2002. Contemporary debates in organizational epistemology. In J. A. C. Baum (Ed.), The Blackwell Companion to Organizations: 733751. Malden, MA: Blackwell Publishing.

Morgan, G. 2006. Images of Organization (Updated ed.). London: Sage Publications.

Niiniluoto, I. 1999. Defending abduction. Philosophy of Science, 66: S436-S451.

Oswick, C., Keenoy, T., \& Grant, D. 2002. Metaphor and analogical reasoning in organization theory: Beyond orthodox. Academy of Management Review, 27: 294-303.

Patton, M. Q. 2002. Qualitative Research \& Evaluation Methods (3rd ed.). London: Sage.

Peirce, C. S. 1877. The fixation of belief. Popular Science Monthly, 12: 1-15.

Peirce, C. S. 1878. Deduction, induction, and hypothesis. Popular Science Monthly, 13: 470-482. 
Peli, G., Bruggeman, J., Masuch, M., \& Ó Nualláin, B. 1994. A logical approach to formalizing organizational ecology. American Sociological Review, 59: 571-593.

Pfeffer, J. 1993. Barriers to the advance of organizational science: Paradigm development as a dependent variable. Academy of Management Review, 18: 599-620.

Pfeffer, J., \& Sutton, R. I. 2006. Hard Facts, Dangerous Half-Truths \& Total Nonsense. Boston: Harvard Business School Press.

Piaget, J. 1971. Insights and Illusions of Philosophy (First American ed.). New York: The World Publishing Company.

Platt, J. R. 1964. Strong inference. Science, 146: 347-353.

Popper, K. R. 1959. The Logic of Scientific Discovery. London: Hutchinson \& Co.

Quine, W. V. 1951. Main trends in recent philosophy: Two dogmas of empiricism. Philosophical Review, 60: 20-43.

Rumelt, R. P., Schendel, D., \& Teece, D. J. 1991. Strategic management and economics. Strategic Management Journal, 12: 5-29.

Salmon, W. C. 1966. The Foundations of Scientific Inference. Pittsburgh, PA: University of Pittsburgh Press.

Salmon, W. C. 1971. Statistical Explanation and Statistical Relevance. Pittsburgh, PA: University of Pittsburgh Press.

Simon, H. A. 1987. Making management decisions: The role of intuition and emotion. Academy of Management Executive, 1: 57-64.

Simon, H. A. 1997. Administrative Behavior (4th ed.). New York: Macmillan.

Stanovich, K. E. 1999. Who Is Rational? Studies of Individual Differences in Reasoning. Mahwah, N.J.: Lawrence Erlbaum Associates. 
Stanovich, K. E. 2011. Rationality and the Reflective Mind. Oxford: Oxford University Press.

Stinchcombe, A. L. 1968. Constructing Social Theories. New York: Harcourt, Brace \& World.

Strauss, A., \& Corbin, J. 1990. Basics of Qualitative Research: Grounded Theory Procedures and Techniques. Newbury Park, CA: Sage Publications.

Suddaby, R., \& Greenwood, R. 2005. Rhetorical strategies of legitimacy. Administrative Science Quarterly, 50: 35-67.

Suddaby, R. 2006. From the editors: What grounded theory is not. Academy of Management Journal, 49: 633-642.

Sutton, R., \& Staw, B. 1995. What theory is not. Administrative Science Quarterly, 40: 371-384.

Thagard, P. R. 1988. Computational Philosophy of Science. Cambridge, MA: MIT Press.

Thagard, P. R. 2007. The moral psychology of conflicts of interest: Insights from affective neuroscience. Journal of Applied Philosophy, 24: 367-380.

Toulmin, S. E. 2003. The Uses of Argument (Updated ed.). Cambridge: Cambridge University Press.

Walton, D. N. 1989. Informal Logic: A Handbook for Critical Argumentation. Cambridge: Cambridge University Press.

Van de Ven, A. H., \& Johnson, P. E. 2006. Knowledge for theory and practice. Academy of Management Review, 31: 802-821.

van Fraassen, B. C. 1980. The Scientific Image. Oxford: Clarendon Press.

Weimer, W. B. 1979. Notes on the Methodology of Scientific Research. Hillsdale, NJ: Lawrence Erlbaum Associates.

Whetten, D. A. 1989. What constitutes a theoretical contribution? Academy of Management Review, 14: 490-495. 
Whewell, W. 1840. The Philosophy of the Inductive Sciences, Founded Upon their History. London: John W. Parker and Son.

Willer, D., \& Webster, M., Jr. 1970. Theoretical concepts and observables. American Sociological Review, 35: 748-757.

Williamson, O. E. 1985. The Economic Institutions of Capitalism. New York: Free Press.

Wodak, R. 2004. Critical discourse analysis. In C. Seale \& G. Gobo \& J. F. Gubrium (Eds.), Qualitative Research Practice: 197-213. Thousand Oaks, CA: Sage Publications.

Wodak, R., \& Meyer, M. 2009. Methods of Critical Discourse Analysis. Thousand Oaks, CA: Sage Publications.

von Wright, G. H. 1971. Explanation and Understanding. Ithaca, NY: Cornell University Press.

Yin, R. K. 2003. Case Study Research: Design and Methods (3rd ed.). Thousand Oaks, CA: Sage Publications. 
Table 1. Normative, descriptive and prescriptive criteria for reasoning

\begin{tabular}{|l|l|l|l|}
\hline $\begin{array}{l}\text { Evaluation } \\
\text { criterion }\end{array}$ & View of human rationality & Reasoning emphasis & Methodological role \\
\hline Normative & $\begin{array}{l}\text { Panglossian: Reasoners are } \\
\text { inherently rational }\end{array}$ & $\begin{array}{l}\text { Following explicit and } \\
\text { formal rules (computation) }\end{array}$ & $\begin{array}{l}\text { Rule-based compliance } \\
\text { toward universal reasoning } \\
\text { standards }\end{array}$ \\
\hline Descriptive & $\begin{array}{l}\text { Apologetic: Reasoners are } \\
\text { not inherently rational and } \\
\text { there is not much we can do } \\
\text { to improve reasoning }\end{array}$ & $\begin{array}{l}\text { Idiosyncratic reasoning } \\
\text { practice }\end{array}$ & $\begin{array}{l}\text { Transparency of reasoning } \\
\text { practice }\end{array}$ \\
\hline Prescriptive & $\begin{array}{l}\text { Meliorist: Reasoners are } \\
\text { inherently neither rational } \\
\text { or irrational, but actions } \\
\text { toward rationality can be } \\
\text { prescribed }\end{array}$ & Researcher cognition & $\begin{array}{l}\text { Negotiated compliance to } \\
\text { local rules }\end{array}$ \\
\hline
\end{tabular}




\section{Table 2. Criteria for evaluating deductive reasoning}

\begin{tabular}{|c|c|c|c|}
\hline & Normative & $\begin{array}{l}\text { Descriptive } \\
\end{array}$ & Prescriptive \\
\hline Deduction & $\begin{array}{c}\text { Universal logical coherence } \\
\text { within a complete system } \\
\text { of arguments }\end{array}$ & $\begin{array}{c}\text { Transparency of premises } \\
\text { and conclusions }\end{array}$ & $\begin{array}{c}\text { Coherence between } \\
\text { premises and conclusions, } \\
\text { negotiated within a } \\
\text { scholarly community }\end{array}$ \\
\hline $\begin{array}{l}\text { Theory } \\
\text { testing }\end{array}$ & $\begin{array}{l}\text { Derivation of hypotheses } \\
\text { from theory deductively } \\
\text { (hypothetico-deductive) }\end{array}$ & $\begin{array}{l}\text { Tractability of the link } \\
\text { between theory and } \\
\text { hypotheses }\end{array}$ & $\begin{array}{c}\text { Explanatory coherence in } \\
\text { linking theory and } \\
\text { hypotheses }\end{array}$ \\
\hline $\begin{array}{r}\text { Inductive } \\
\text { case }\end{array}$ & $\begin{array}{l}\text { Not applicable: } \\
\text { Deduction is outside the } \\
\text { normative scope of case } \\
\text { research }\end{array}$ & $\begin{array}{l}\text { Tractability in motivating } \\
\text { the research problem }\end{array}$ & $\begin{array}{l}\text { Coherence in motivating } \\
\text { research problem }\end{array}$ \\
\hline Interpretive & $\begin{array}{c}\text { Not applicable: } \\
\text { Deduction is outside the } \\
\text { normative scope of } \\
\text { interpretive research }\end{array}$ & $\begin{array}{l}\text { Transparency of deductive } \\
\text { chains in interpretive } \\
\text { inferences }\end{array}$ & $\begin{array}{l}\text { Narrative coherence in } \\
\text { deductive chains in } \\
\text { interpretive inferences }\end{array}$ \\
\hline
\end{tabular}




\section{Table 3. Criteria for evaluating inductive reasoning}

\begin{tabular}{|r|l|l|l|}
\hline Induction & \multicolumn{1}{|c|}{ Normative } & \multicolumn{1}{c|}{ Descriptive } & \multicolumn{1}{c|}{ Prescriptive } \\
\hline $\begin{array}{r}\text { Generalizability and } \\
\text { predictive power of } \\
\text { arguments }\end{array}$ & $\begin{array}{l}\text { Transparency of the link } \\
\text { between data and empirical } \\
\text { generalizations }\end{array}$ & $\begin{array}{l}\text { Robustness of empirical } \\
\text { evidence for } \\
\text { generalizations }\end{array}$ \\
\hline Interpretive & $\begin{array}{l}\text { Theoretical propositions } \\
\text { emerge from empirical } \\
\text { data, unbiased by } \\
\text { researcher interpretation }\end{array}$ & $\begin{array}{l}\text { Not applicable: } \\
\text { of coding (generalizing } \\
\text { from data) }\end{array}$ & $\begin{array}{l}\text { Impartiality of the } \\
\text { empirical generalization } \\
\text { not addressed by } \\
\text { methodological literature }\end{array}$ \\
\hline $\begin{array}{r}\text { Theory } \\
\text { testing }\end{array}$ & $\begin{array}{l}\text { Induction is not to be used; } \\
\text { theories are tested from } \\
\text { falsifying evidence by } \\
\text { deduction }\end{array}$ & $\begin{array}{l}\text { Transparency in analogical } \\
\text { reasoning }\end{array}$ & $\begin{array}{l}\text { Credibility of analogical } \\
\text { reasoning and } \\
\text { appropriateness of } \\
\text { metaphors }\end{array}$ \\
\hline
\end{tabular}




\section{Table 4. Criteria for evaluating abductive reasoning}

\begin{tabular}{|r|l|l|l|}
\hline Abduction & \multicolumn{1}{|c|}{ Normative } & \multicolumn{1}{|c|}{ Descriptive } & \multicolumn{1}{c|}{ Prescriptive } \\
& $\begin{array}{l}\text { Selecting “the best } \\
\text { explanation" }\end{array}$ & $\begin{array}{l}\text { Transparency of selection } \\
\text { between alternatives }\end{array}$ & $\begin{array}{l}\text { Compliance to local } \\
\text { principles in selecting } \\
\text { between alternatives }\end{array}$ \\
\hline Interpretive & $\begin{array}{l}\text { Credibility in theoretical } \\
\text { interpretation }\end{array}$ & $\begin{array}{l}\text { Reflexivity in theoretical } \\
\text { interpretation }\end{array}$ & $\begin{array}{l}\text { Credibility in theoretical } \\
\text { interpretation }\end{array}$ \\
\hline $\begin{array}{r}\text { Theory } \\
\text { testing }\end{array}$ & $\begin{array}{l}\text { Abductive reasoning must } \\
\text { not be used; “the best } \\
\text { explanation" must be } \\
\text { sought through elimination } \\
\text { of alternatives using } \\
\text { computational inductive } \\
\text { reasoning }\end{array}$ & $\begin{array}{l}\text { Transparency of the } \\
\text { selection between } \\
\text { alternatives } \\
\text { (operationalizations, } \\
\text { theoretical interpretations) }\end{array}$ & $\begin{array}{l}\text { Credibility of the selected } \\
\text { between alternatives } \\
\text { (operationalizations, } \\
\text { theoretical interpretations) }\end{array}$ \\
\cline { 2 - 4 } & $\begin{array}{l}\text { Visibility of researcher } \\
\text { interpretation in } \\
\text { entertaining and selecting } \\
\text { from alternative } \\
\text { explanations in theoretical } \\
\text { interpretation }\end{array}$ & $\begin{array}{l}\text { Credibility of the selected } \\
\text { explanation }\end{array}$ \\
\hline
\end{tabular}

